\title{
Cooperativismo de saúde, mais de meio século de inovações e conquistas atento aos princípios e valores cooperativos
}

\author{
Health cooperativism, more than a half century of innovations \\ and achievements attention to cooperative principles \\ and values
}

Paulo Roberto Cardoso Braga ${ }^{1}$

Sumário: 1. Introdução: Breve história do cooperativismo de saúde brasileiro; 2. Identidade cooperativa e princípios cooperativos; 3. Motivação do sucesso do cooperativismo de saúde brasileiro; 4. Conclusões. Referências.

Resumo: O presente trabalho disserta acerca da constituição e o desenvolvimento do ramo cooperativo saúde, modelo cooperativista genuinamente brasileiro, fruto do ideal de médicos na busca por oferecer atendimento de excelência aos usuários, sempre focado na aplicação prática dos princípios e valores cooperativos, sem esquecer da aplicação da legislação de regência cooperativa e princípios constitucionais pertinentes a saúde suplementar. Valores, princípios, ética e sua estrutura face a correta exegese do cooperativismo de saúde.

Palavras-chave: Cooperativismo de saúde; Valores cooperativos; Princípios cooperativos; Sistema de saúde suplementar.

Resumen: Este artículo discute la constitución y desarrollo de la rama cooperativa SAÚDE, un modelo cooperativo genuinamente brasileño; fruto del ideal de los médicos en la búsqueda de ofrecer una excelente atención a los

1 Especialista em Direito de Empresa pelo IEC-PUC-MG, graduado pela Faculdade de Direito da Universidade Federal de MG. Advogado atuante, sócio titular da Paulo Braga Advogados Associados, referência em direito cooperativo. Professor convidado de cursos de MBA direcionados para o setor cooperativo e empresarial. Membro das seguintes comissões: Comissão de Direito Cooperativo da OAB/MG; Grupo de Trabalho Institucional-CNCOOP-Confederação Nacional das Cooperativas - GT/CCT NACIONAL. Comitê jurídico do sistema UNICRED e Comitê jurídico da FECOOP-SULENE. E-mail: paulobraga@paulobragaadvogados.com.br 
usuarios, siempre enfocados a la aplicación práctica de los principios y valores cooperativos, sin olvidar la aplicación de la legislación de regulación cooperativa y los principios constitucionales relevantes para la salud complementaria. Valores, principios, ética y su estructura de cara a la correcta exégesis de las cooperativas de salud.

Palabras clave: Cooperativas de salud; Valores cooperativos; Principios cooperativos; Sistema de salud complementario. 


\section{Introdução: Breve história do cooperativismo de saúde brasileiro}

Brilhante pergunta formulada pelo Dr. Orestes Pullin, atual presidente da Unimed do Brasil: Como seria a saúde brasileira hoje sem o sistema UNIMED? ${ }^{2}$

Para responder a instigante pergunta e entendermos o cooperativismo de saúde, ramo cooperativo genuinamente brasileiro, precisamos voltar no tempo, mais precisamente no final da década de 1960, quando a medicina assistencial no Brasil vivia um momento de grande ebulição face as transformações complexas na estrutura da Previdência Social.

Neste contexto em que o sistema previdenciário pátrio passou por profundas alterações, primeiro com a unificação dos Institutos de Aposentadorias e Pensões (IAPs) no Instituto Nacional de Assistência Médica de Previdência Social (INPS), depois na transformação do INPS no Instituto Nacional de Assistência Médica da Previdência Social (INAMPS), por fim extinto em 1990 com a implantação do Sistema Único de Saúde, popular SUS, fruto das disposições constitucionais de 1988.

A Lei Orgânica da Previdência Social de 1960, Lei n. ${ }^{\circ} 3.807 / 1960$, popularmente conhecida como LOPAS estabeleceu um marco de unificação e uniformização das normas infraconstitucionais existentes sobre a Previdência Social em nosso ordenamento jurídico, sendo considerado o maior passo na universalização da previdência social em nosso país.

Importante frisar que a Constituição Federal de 1967, em seu artigo 158 trouxe a lume diversos direitos trabalhistas e previdenciários, sendo a primeira a prever a concessão do seguro-desemprego em nosso ordenamento jurídico.

Nesse cipoal de normas, alterações nos costumes mundiais, já que a década de 60 foi marcada por muitas revoluções, algumas pacíficas, outras não, a categoria profissional dos médicos não passou despercebida, pelo contrário: com o surgimento de seguradoras de saúde, crescente mercantilização da medicina com a queda no padrão de atendimento, o profissional médico estava cada vez mais tendo dificultadas de exercer a medicina com dignidade e liberdade, fazendo jus ao juramento de Hipócrates.

Desta forma, um grupo de médicos filiados ao Sindicato dos Médicos de Santos (SP), insatisfeito com esta situação, buscou um modelo que resgatasse a ética e o papel social da medicina, garantindo a prática liberal da profissão e a qualidade do atendimento.

2 http://memoria.unimed.coop.br/memoria/arquivos/detalhes/99 
Edmundo Castilho e mais 22 médicos fundaram, então, em 18 de dezembro de 1.967, a União dos Médicos-Unimed, na cidade de Santos (SP), com base nos princípios e valores do cooperativismo.

Mas qual o diferencial Unimed?

Sem dúvida alguma, o cooperativismo, especialmente a gestão democrática, que nas palavras do finado Presidente da República do Brasil, Tancredo Neves: "As cooperativas são as instituições mais democráticas que existem.»

A participação dos cooperados é essencial para o sucesso do empreendimento cooperativo e no sistema UNIMED tal assertiva é verdadeira, estando o sistema UNIMED presente em todo o território nacional, sendo composto por 345 (trezentos e quarenta e cinco) cooperativas com 116 (cento e dezesseis) mil médicos cooperados atendendo 17 milhões de beneficiários. A estrutura UNIMED possui 126 (cento e vinte e seis) hospitais próprios e 2.372 (dois mil, trezentos e setenta e dois) hospitais credenciados, bem como pronto atendimentos, laboratórios e ambulâncias, tudo em prol na excelência no atendimento.

Tudo isso se traduz em uma participação de 37\% (trinta e sete) por cento no sistema de saúde suplementar nacional, líder de mercado.

O sistema cooperativo UNIMED é composto da seguinte forma3

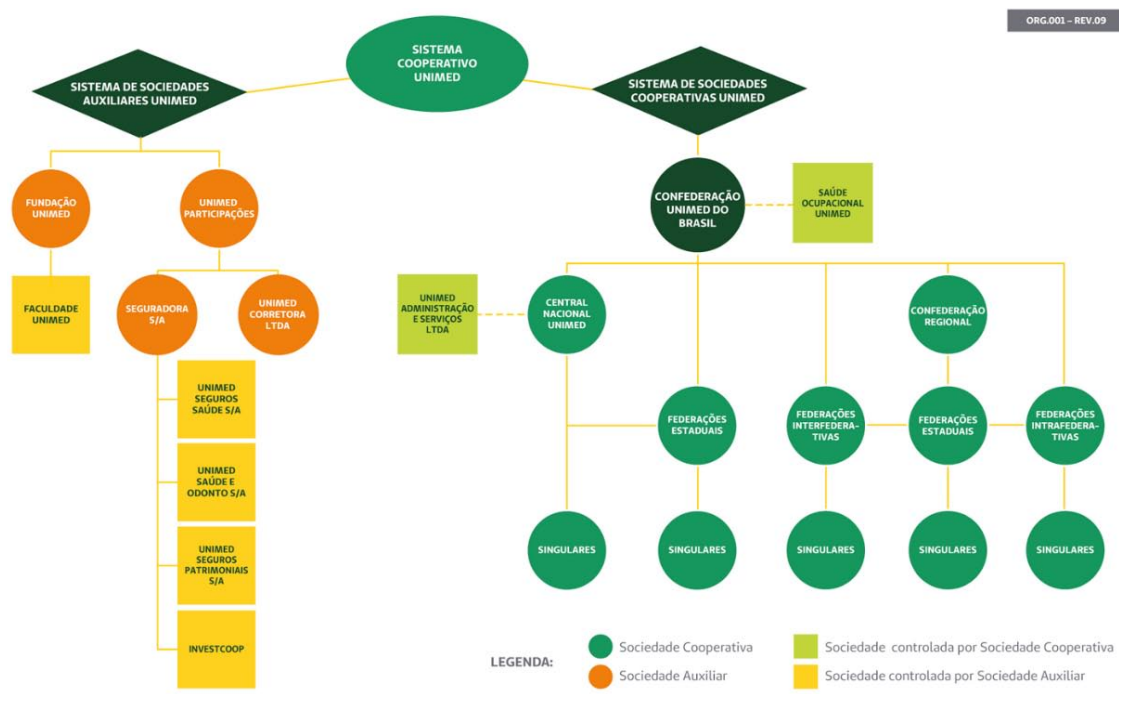

3 https://www.unimed.coop.br/home/sistema-unimed/a-unimed 
Como sistema cooperativo, composto por uma confederação nacional, uma central nacional, federações estaduais, federações intrafederativas e singulares, além de empreendimentos de cunho complementar a atividade primordial cooperativa, constituiu-se um novo e promissor ramo do cooperativismo.

Os precursores do novo ramo cooperativo, visando dar atendimento médico de excelência aos usuários do sistema UNIMED, nacionalmente, organizaram um arranjo de atendimento denominado Intercâmbio Nacional, que é o atendimento do beneficiário de uma Unimed por outra, desde que seu plano contratado permita a prática.

Desta forma, legalmente, conseguiu dar atendimento nacional ao usuário nas situações contratadas, mesmo sendo a origem do atendimento limitado a determinada área de atuação da cooperativa singular, conforme determinado em seu estatuto social.

Criatividade e ousadia para crescer o negócio de forma sustentada e necessária a proteger os usuários do sistema UNIMED em seus deslocamentos pelo território nacional.

O sistema de intercâmbio UNIMED é uma forte demonstração prática da aplicação do sexto princípio cooperativo, princípio da intercooperação, o qual se caracteriza pela cooperação entre cooperativas para atingir um benefício comum e amplo, na espécie o atendimento dos usuários dos serviços UNIMED em todo o território nacional.

Como dito pelo mestre Ronaldo Ernesto Scucato, ícone do cooperativismo mundial:

O cooperativismo materializa o trabalho conjunto, inclusivo, com propósito. Por isso, nosso segmento atravessa gerações e gerações demonstrando que a união de pessoas com as mesmas aspirações, nos âmbitos social e econômico, é o caminho para o desenvolvimento. As cooperativas não apenas trabalham de maneira coletiva e democrática, como também têm como ideal contribuir permanentemente para a sustentabilidade. ${ }^{4}$

Assim apresentado de forma breve a origem do sistema UNIMED, precursor mundial do ramo cooperativismo de saúde, vamos abordar os princípios e valores cooperativos e a identidade cooperativa UNIMEDIANA no mundo cooperativo.

4 Jornal Cooperação. Editorial. Ano XV, junho 2018. Ed. 320. 


\section{Identidade cooperativa e princípios cooperativos}

As diretrizes emanadas desde os primórdios da cooperação, com os pioneiros de Rochdale que se consubstanciaram nos princípios cooperativos, em nossa legislação, previstos no artigo $4 .^{\circ}$ da Lei 5764/71, delimitam as diferenças das sociedades cooperativas para as demais sociedades de natureza civil ou comercial presentes em nosso ordenamento jurídico.

O douto ministro do C. STJ, Edson Vidigal, assim se manifestou prefaciando obra pertinente ao direito cooperativo:

Entidades de portas abertas, na qual a adesão e a retirada acontecem com ampla liberdade. As cooperativas de crédito trazem a marca da democracia na sua gestão. As decisões administrativas são tomadas em assembleias gerais e, nelas, é clausula pétrea o princípio «um associado, um voto. ${ }^{5}$

Os pioneiros de Rochdade ao evoluírem o conceito de cooperativismo já existente, trazendo para o século XIX a cooperação em sua forma atual, basearam a relação entre os associados e as cooperativas e destas para com a sociedade em geral, em sete pilares básicos hoje reconhecidos internacionalmente pela ACl-Aliança Cooperativa Internacional.

Os princípios norteadores são:

I. Adesão livre e voluntária;

II. Gestão democrática;

III. Participação econômica;

IV. Autonomia e independência;

V. Educação, formação e informação;

VI. Intercooperação e,

VII. Interesse pela comunidade.

A citada lei cooperativista, estabeleceu onze princípios, desdobrando alguns princípios norteadores a fim de enfatizar a importância dos mesmos. Os princípios estão insculpidos nos incisos I a XI do artigo 4. ${ }^{\circ}$, assim descritos:

I. adesão voluntária, com número ilimitado de associados, salvo impossibilidade técnica de prestação de serviços;

II. variabilidade do capital social representado por quotas-partes;

5 VIDIGAL, Edson. Aspectos Jurídicos das Cooperativas de Crédito. Belo Horizonte: Mandamentos, 2005, prefácio. 
III. limitação do número de quotas-partes do capital para cada associado, facultado, porém, o estabelecimento de critérios de proporcionalidade, se assim for mais adequado para o cumprimento dos objetivos sociais;

IV. incessibilidade das quotas-partes do capital a terceiros, estranhos à sociedade;

$V$. singularidade de voto, podendo as cooperativas centrais, federações e confederações de cooperativas, com exceção das que exerçam atividade de crédito, optar pelo critério da proporcionalidade;

VI. quórum para o funcionamento e deliberação da Assembleia Geral baseado no número de associados e não no capital;

VII. retorno das sobras líquidas do exercício, proporcionalmente às operações realizadas pelo associado, salvo deliberação em contrário da Assembleia Geral;

VIII. indivisibilidade dos fundos de Reserva e de Assistência Técnica Educacional e Social;

IX. neutralidade política e indiscriminação religiosa, racial e social;

$\mathrm{X}$. prestação de assistência aos associados, e, quando previsto nos estatutos, aos empregados da cooperativa;

XI. área de admissão de associados limitada às possibilidades de reunião, controle, operações e prestação de serviços.

Identidade cooperativa e princípios cooperativos estão umbilicalmente ligados, sendo um decorrente do outro.

A identidade cooperativa decorre da aplicação correta dos princípios cooperativos. Mesmo estando o mundo em constante transformação, notadamente nas últimas décadas, fruto do notável e perturbador avanço tecnológico, as sociedades cooperativas mantem, integralmente, a aplicação dos princípios em seu cotidiano, já que se desviar do seu fim, as cooperativas poderão se transformar em sociedades comuns, sem a liga que lhe dá vida.

Já em 1995, em Manchester, a Aliança Cooperativa Internacional alertava para essa realidade e para as suas repercussões quando anunciou a declaração sobre identidade cooperativa baseada na definição, nos valores e nos princípios.

Sobre a definição de cooperativa diz a declaração da ACl:

Uma cooperativa é uma associação autônoma de pessoas, que se unem, voluntariamente, para satisfazer necessidades e aspirações econômicas, sociais e culturais comuns, através de uma empresa de propriedade conjunta e democraticamente controlada»

As cooperativas baseiam-se em valores de autoajuda e responsabilidade própria, democracia, igualdade, equidade e solidariedade. $\mathrm{Na}$ 
tradição dos seus fundadores, os membros das cooperativas acreditam nos valores éticos da honestidade, transparência, responsabilidade social e preocupação pelos outros.

Esses princípios implicam na forte identidade cooperativa de se preocupar com o social sem se esquecer do econômico, já que a origem da aventura dos pioneiros de Rochdale (1844) é uma cooperativa de consumo que visava oferecer aos associados bens a preço justo, facilitando a aquisição de produtos básicos e indispensáveis a sobrevivência da população.

Ao participar, ativamente, da vida social das comunidades estamos vendo a aplicação prática do sétimo princípio, qual seja: interesse pela comunidade.

A moderna doutrina cooperativista tem conceituado princípio como valor cooperativo, como nos ensina, com peculiar propriedade, Leonardo Rafael de Souza, capítulo 2, destacando a seguinte passagem, páginas 29 e 30:

Não obstante essa importante evolução, o que se nota até aqui é que os valores constituem uma resposta natural às necessidades sentidas pelo sujeito a partir das qualidades a serem por si apreciadas... ${ }^{6}$

Assim conceituar valor significa o considerar como uma possibilidade de escolha, isto é, «uma disciplina inteligente das escolhas, que pode conduzir a eliminar alguma delas ou declará-las irracionais ou nocivas, e poder conduzir (e conduz) a privilegiar outras, prescrevendo a sua repetição cada vez que determinadas condições se verifiquem. (ABBAGNANO, 1982, p. 956)

Trabalho publicado por Francisco de Borja García García7 na conferência ICA 2016, realizada em Almeria, Espanha, faz uma interligação entre cooperativismo e economia, especialmente no constante aprimoramento dos princípios e valores cooperativos face a necessidade econômica dos associados.

García, ensina com propriedade "The cooperative values are the set of rules which must be satisfied by a cooperative so that the latter is regarded as such» (Sanchez, 1995).

6 SOUZA, Leonardo Rafael de. Cooperativas de crédito: regulação do CMN e os valores cooperativos. Curitiba: Juruá, 2017.

7 GARCÍA GARCÍA, Francisco de Borja. The relevance of the principles of co-operatism within Co-operative Law. file:///C:/Users/Usuario/Documents/3\%20-\%20PBAA Doutrina/Cooperativismo/Francisco_de_Borja_Garc_a_Garc_a._The_relevance_of_the_ principles_of_co-operatism_Within_Co-operative_Law.pdf 
The co-operative values have been modified in accordance with the evolution of its economic environment providing the co-operatives with identity (Ring, 1992)

The cooperation originally emerged as a labour movement which rebels against the capitalist production system of the industrial revolution. Its purposes were to defend and represent collectivelly the interests of the working classes.

To that end, they try to overcome social problems, such as poor working conditions or coverage of basic services, which neither companies nor the state were able to solve, or didn't want to, through activism. This fight for worker's rights would show a slow process in Europe (Blanco, 1985).

Mais adiante, García aborda um novo subvalor, qual seja: o interesse da cooperativa se sobrepõe ao interesse do associado. Este novo subprincípio coloca um dever de cooperação entre os membros, a fim de alcançar a sobrevivência da sociedade.

Da mesma forma, protege seus interesses, uma vez que esse subvalor leva à criação de um conceito jurídico que visa a busca pela sobrevivência da entidade cooperativa.

Vejamos o texto original:

The co-operative juridical concept is subjected to the co-operative values of Manchester 1995.

However, the interpretation of the law shows that the differences between the principal values; "Open doors" and "Democratic principles" results in a new sub-value: "the cooperative 's interest is above the individual's interest".

This new sub-principle places a duty of co-operation among members in order to achieve the survival of society. Likewise, it protects their interests since this sub- value leads to the creation of a legal concept whose aim is to look for survival.

Abordando o tema, Alejandro Martínez Chaterina, em artigo intitulado "Los valores y los princípios cooperativos» nos ensina com a propriedade que lhe é peculiar:

El reciente Congreso centenário de la Alianza Cooperativa Internacional de Manchester há puesto de relieve el hecho de que hoy, más que nunca, las cooperativas tratan de encontrar su propia identidade.

La historia de las cooperativas es hasta certo punto la historia de la búqueda de sua identidade señalaba Lars Marcus em el Congreso de la $\mathrm{ACl}$ de Estocolmo de 1.988. Em efecto, los princípios coopera- 
tivos heredados de la tradición cooperativa a partir de la experiencia de Rochdale y administrados con posterioridade por la Alianza Cooperativa Internacional, han sido elementos identificadores de las cooperativas que han permitido delimitarlas diferenciándolas de otras realidades sociales $\mathrm{Y}$ empresariales em el tempo. ${ }^{8}$

Doutrina de minha autoria, na obra Direito Cooperativo e Identidade Cooperativa, publicação coordenada Miranda, Souza e Gadea já destacava a temática dos princípios e valores cooperativos, vejamos:

O que vem a ser princípio no âmbito do regramento jurídico? Pergunta fundamental já que sua resposta irá determinar ou não a aplicação dos mesmos, por parte dos julgadores no caso concreto. Princípio cooperativo ou valor cooperativo está intrinsicamente ligado a gênese cooperativa e a identidade cooperativa. Sem valor cooperativo não temos identidade cooperativa. ${ }^{9}$

Assim sendo, nunca podemos pensar aplicação de normas ou regras jurídicas as relações cooperativas ou relações decorrentes da prática do cooperativismo sem que a exegese cooperativa faça parte da aplicação das normas.

Segundo Carvalho Filho, tanto os princípios como as regras poderiam enquadrar-se no gênero normas jurídicas, estando as regras no plano de validade (regra «a» X regra «b»), tendo por consequência a exclusão de uma delas) e os princípios no plano da ponderação, cuja consequência seria a utilização dos princípios conforme o grau de preponderância de cada um deles. ${ }^{10}$

De fato, além do reconhecimento da natureza normativa dos princípios pela doutrina e pela jurisprudência, reconhece-se também a sua eficácia mais intensa do que a da própria regra.

O princípio possui em sua origem os próprios valores da sociedade, congregando determinação e valor. Esta é a lição de José Ricardo Cunha11:

A grande virtude, pois, dos princípios é esta capacidade de condensar numa unidade operacional os aspectos axiológicos e deontológicos da normatividade jurídica, revelando que o dever ser das

8 CHATERINA, Alejandro Martínez. REVESCO: revista de estudios cooperativos, ISSN 1135-6618, n. ${ }^{\circ}$ 61, 1995 (Exemplar dedicado a: La identidad cooperativa), páginas 35-46.

9 BRAGA, Paulo Roberto Cardoso. Identidade cooperativa e o processo administrativo sancionador: princípios cooperativos e constitucionais face a aplicação da lei n. ${ }^{\circ}$ 13.506/2017. In Miranda, José Eduardo et al. Direito Cooperativo e Identidade Cooperativa-Editora Brazil Publishing, 2019.

10 CARVALHO FILHO, José dos Santos. (2006), Manual de Direito Administrativo. 15. ${ }^{\text {a. }}$ Rio de Janeiro: Lumen Juris.

11 CUNHA, José Ricardo. (2006), Sistema aberto e princípios na ordem jurídica e na metódica constitucional. 2. ${ }^{a}$ ed. Rio de Janeiro: Lúmen Juris. 
imperatividades do direito não pode ser dissociado de um núcleo ontológico que resguarde uma eticidade necessária à consecução dos fins do direito.

Assim, o comando (dever ser) não pode ser separado do valor que lhe justifica, impedindo que o direito seja reduzido à pura força ou violência institucional, muito embora não prescinda dela.

Os princípios cooperativos também são valores éticos, sendo a ética intrínseca ao princípio, não podendo dela se dissociar; pelo contrário estão juntos, unos em um só mecanismo que valoriza a concepção dos pioneiros Rochdale, hoje presentes nas diretrizes da $\mathrm{ACl}$.

Juan Luis Moreno Fontela, comentando sobre o tema no artigo que aborda as relações entre os valores e os princípios cooperativos e os princípios da norma cooperativa, nos ensina o seguinte:

La Declaración Sobre la Identidad Cooperativa de 1995 incluye un Informe sobre la declaración que cita como soportes conceptuales de la Declaración dos trabajos preparatorios, el informe Cooperative Values in a Changing World de Sven Ake Böök (Böök, 1992) y el estudio de Watkins, Cooperative Principles: Today and Tomorrow (Watkins, 1986).

El informe Cooperative Values in a Changing World describe los valores cooperativos como las concepciones de los cooperativistas sobre lo que es bueno, deseable y merece ser perseguido para mejorar las condiciones de vida humana. De acuerdo con esta concepción, todos los valores cooperativos a los que se refiere la $\mathrm{ACl}$ en la Declaración Sobre la Identidad Cooperativa son valores éticos (tanto los que la Declaración denomina solo valores cooperativos, como los que califica expresamente como valores éticos), en tanto que todos ellos son valores relacionados con el desarrollo personal de los seres humanos. ${ }^{12}$

Os valores e princípios cooperativos têm correlação muito forte com os valores éticos da sociedade na qual a cooperativa está inserida, muitas vezes os valores cooperativos agregam ética as relações entre os associados e a cooperativa e entre os associados e a comunidade em geral, contribuindo para o crescimento de toda comunidade envolvida com o processo cooperativo.

Os princípios cooperativos juntamente com os valores cooperativos da auto ajuda, interesse pela comunidade, educação e formação, gestão democrática são valores éticos e caros as cooperativas do sistema

12 MORENO Fontela, Juan Luis. Revesco .(124) 2017: 114-127. Las relaciones entre los valores y principios cooperativos y los principios de la normativa cooperativa. 
UNIMED que não medem esforços para contribuir com uma sociedade na qual a oferta de serviços e produtos de saúde sejam prestados em condições de acesso a grande parte da população.

O cooperativismo de saúde, ramo cooperativo brasileiro fruto da constituição do sistema UNIMED sempre se pautou pela observância dos princípios e valores cooperativos, constando da missão institucional a integração de todo o sistema, fortalecendo os princípios cooperativistas e valorizando o trabalho médico.

Conseguiu o sistema UNIMED consolidar o anseio de todo médico, qual seja: cuidar bem de seu paciente, dando cumprimento ao princípio cooperativo de interesse pela comunidade, interiorizando o atendimento médico em todos os rincões brasileiros.

\section{Motivação do sucesso do cooperativismo de saúde brasileiro}

Podemos doravante responder à pergunta inicial formulada pelo Dr. Orestes Pullin, atual presidente da Unimed do Brasil: Como seria a saúde brasileira hoje sem o sistema UNIMED?

Certamente a saúde suplementar nacional não estaria presente em diversas localidades com a qualidade do serviço prestado pelos cooperativistas, associadas das cooperativas, com o caráter humanista e solidário que é peculiar ao cooperativismo.

O cooperativismo é extremamente solidário, agregador de pessoas e atitudes proativas para o desenvolvimento social, sempre almejando o bem comum de todos.

O cooperativismo, não importa o ramo, é a terceira via econômica entre o capitalismo e o socialismo e suas diversas matrizes. No cooperativismo o equilíbrio entre a busca pelo resultado positivo, a justa remuneração de todos os atores envolvidos e o bem estar social justificam o sucesso do empreendimento cooperativo.

A história do cooperativismo desenvolvido pela UNIMED é única no mundo da cooperação, sobretudo o sucesso alcançado, disponibilizando a população serviços de excelência e proporcionando aos cooperados a oportunidade de trabalho digno que todo profissional médico quer prestar ao seu cliente.

Decorridos mais de 50 (cinquenta) anos da constituição do sistema cooperativo UNIMED, os princípios e valores cooperativos estão presentes no dia a dia das cooperativas médicas, dos cooperados e dos usuários dos serviços prestados.

Verdadeiro legado de saúde complementar para toda a nação brasileira, fruto de respeito mútuo entre o médico e o usuário, voltado 
para atender a necessidade primordial de se ter saúde e atendimento médico de excelência a custo suportável por todas as partes envolvidas.

A abordagem cooperativa é mais correta do ponto de vista moral e ético, portanto mais inteligente ao aglutinar o prestador do serviço médico (cooperado) diretamente ao usuário dos serviços prestados pela cooperativa, aplicando o princípio da primazia da solidariedade como baluarte principal da atividade cooperativa no setor de saúde.

A união entre os médicos, aplicando os princípios e valores cooperativos no dia a dia da sociedade cooperativa, em sua gestão, na governança cooperativa e, sobretudo no atendimento humanizado aos usuários dos planos contratados, motiva o sucesso do empreendimento cooperativo de saúde pátrio.

O cooperativismo na visão dos pioneiros de Rochdale traz em seu bojo a preocupação com o social, com a sustentabilidade e com a governança, muito antes destes temas serem caros a toda a sociedade mundial. Não podemos esquecer o cooperativismo moderno iniciou-se com a Sociedade dos Probos Pioneiros de Rochdale nos idos de 1844.

Sendo da essência do cooperativismo a união de forças para alcançar objetivos comuns, não resta dúvida de que grande parte do sucesso do sistema UNIMED decorre da participação ativa dos associados que são «donos do negócio», participando ativamente e igualitariamente das decisões da cooperativa (lembrando que é um princípio cooperativo: um homem, um voto); podendo defender suas ideias nas plenárias e assembleias gerais.

Por outro lado, como as cooperativas não visam lucros, elas podem oferecer melhores preços à população e ainda remunerar adequadamente seus cooperados, que também recebem parte dos resultados caso haja sobras. Trata-se, portanto, de um modelo benéfico para todos os envolvidos.

O grande filósofo e espiritualista italiano, Pietro Ubaldi ajuda a entender uma das razões do sucesso do empreendimento cooperativo, ao nos presentear que "o próximo grande salto evolutivo da humanidade será a descoberta de que cooperar é melhor que competir».

O cooperativismo não estimula a competição entre seus membros; pelo contrário. Desta forma a cooperação reflete na qualidade dos atendimentos aos usuários, bem como o relacionamento entre os cooperados estimula o crescimento coletivo em detrimento do individual, essência da cooperação.

Max Gehringer com a habitual inteligência pontua que:

O cooperativismo é a mais antiga maneira de transformar habilidades individuais em resultados coletivos, que não seriam atingidos apenas com esforço próprio. 
O cooperativismo ensina a dar valor à contribuição dos demais, a trabalhar em equipe, a ajudar quem necessita. Esses são fatores que irão dar combustível a qualquer carreira, em qualquer empresa, de qualquer ramo. ${ }^{13}$

Outro fator importante que justifica o sucesso do cooperativismo de saúde é o seu constante investimento em educação, base do quinto princípio: educação, formação e informação.

A Fundação Unimed (Faculdade Unimed) tem como finalidade o desenvolvimento e manutenção de serviços educacionais nas áreas de saúde, gestão e cooperativismo.

Destacando a aplicação dos princípios e valores cooperativos, especialmente os princípios de gestão democrática, participação econômica, educação, intercooperação e interesse pela comunidade, os sistema UNIMED é exemplo a ser seguido por todos os ramos do cooperativismo mundial e, especialmente ser implementado em outros países objetivando oferecer aos médicos melhores condições de trabalho com justa remuneração e a comunidade em geral, acesso a um sistema de saúde suplementar de qualidade com custo acessível.

Não resta dúvida ser a cooperação elemento intrínseco ao ser humano que desde tempos imemoriais busca cooperar para crescer, para progredir, para solucionar os grandes temas que impulsionaram a raça humana, pena que as vezes elementos sem o discernimento cooperativo preferiram competir do que colaborar, violando a máxima de Pietro Ubaldi.

Destacamos que muitos motivos podem ser apontados, como a própria natureza do modelo cooperativo e o profissionalismo com que tem sido conduzido no sistema UNIMED.

Mas a razão mais forte é seu propósito, o porquê de sua criação, buscando unir cada vez mais pessoas que acreditam na força da coletividade para, juntos, disporem de uma fonte própria de trabalho para os cooperados e de saúde suplementar para os usuários dos serviços que transforma suas vidas pessoais e familiares e contribuir para a transformação da vida dos associados e das comunidades nas quais vivem e trabalham.

No transcurso da pandemia COVID-19, as cooperativas médicas mais uma vez mostraram a forte presença dos princípios e valores cooperativos no atendimento das necessidades dos usuários e de toda comunidade em geral.

13 GEHRINGER, Max. Anuário do Cooperativismo. Brasil: 2018. 
Nas palavras do Dr. Orestes Pullin:

Todas as cooperativas, independentemente de seus ramos, são regidas por sete princípios fundamentais, linhas orientadoras por meio das quais levam os seus valores à prática. O sétimo deles diz respeito ao interesse pelas comunidades, onde as cooperativas devem investir, por meio de políticas aprovadas por seus membros, no desenvolvimento sustentável das cidades e regiões nas quais estão inseridas. Preza-se essencialmente por aportes em projetos economicamente viáveis, ambientalmente corretos e socialmente justos.

No contexto da saúde, isso significa zelar pela integridade das populações locais ao mesmo tempo em que se contemplam projetos para aumentar o acesso às principais inovações da assistência médica, entendendo e levando em consideração as necessidades específicas de cada localidade. E isto, no cenário atual de pandemia, nunca foi tão vital.

O elo das cooperativas com a sociedade é muito forte. Seu modelo econômico é baseado na união das pessoas com um mesmo objetivo. Destacam-se principalmente por atuar em favor da sustentabilidade e do desenvolvimento econômico e social da comunidade. E com o fortalecimento da economia colaborativa em tempos de pandemia, têm ganhado cada vez mais espaço.

Infelizmente, ainda não vislumbramos uma cura para a COVID-19. Mas valores como cooperação, diversidade, liberdade e responsabilidade, no sentido de promover o acesso de qualidade às melhores soluções de saúde a cada vez mais pessoas, seguirão presentes neste momento desafiador. ${ }^{14}$

Dentre as diversas cooperativas que compõem o sistema UNIMED, destacamos a UNIMED-BH, presidida pelo Dr. Samuel Flam, exemplo de ente cooperativo que aplica, constantemente os princípios e valores cooperativos nas relações sociais e com a comunidade em geral. No transcurso da pandemia COVID-19, sua atuação é destacada nacionalmente por ter já em 03/02/2020 constituído comitê de crise visando estudar e propor soluções para o enfrentamento correto da pandemia e seus efeitos.

No depoimento do Dr. Samuel Flam, instado por este que escreve o presente artigo, nos brindou com as seguintes informações:

Pautada nos sete princípios cooperativistas, se propôs a promover uma contribuição social efetiva com suas ações de enfrenta-

14 http://www.mundocoop.com.br/artigos/o-cooperativismo-em-tempos-depandemia-orestes-pullin-e-presidente-da-unimed-do-brasil.html 
mento. Apostando em sua expertise em saúde, o objetivo foi gerar e estimular ações positivas em cadeia, promovendo maior segurança sanitária e influenciando efetivamente o desenvolvimento do cenário epidemiológico em sua área de atuação. Tanto que um dos primeiros movimentos da Cooperativa neste contexto de pandemia foi a união de esforços com entidades médicas e cooperativistas para a emissão de um posicionamento único em defesa do isolamento social, que trouxe o mote «Não é por um. É por todos», veiculada pelos principais meios de comunicação de Belo Horizonte. A iniciativa reforça o compromisso da Unimed-BH com o princípio da Intercooperação. ${ }^{15}$

Dentre as ações, destaca-se também o pioneirismo da Cooperativa no lançamento da Consulta On-line Coronavírus, realizado no dia 18 de março, apenas sete dias após a declaração oficial da pandemia. O modelo assistencial tem como premissa evitar a ida de pacientes com sintomas suspeitos aos pronto-atendimentos e, com isso, reduzir o risco de mais contaminações. Além disso, os clientes com sintomas suspeitos passaram a ser telemonitorados pela equipe assistencial da Unimed-BH, que avalia a evolução do quadro clínico e indica o melhor percurso assistencial. Até o final de setembro, a Unimed-BH já havia realizado quase 100 mil consultas on-line e cerca de 125 mil clientes haviam passado pelo telemonitoramento.

A ferramenta de teleconsulta ${ }^{16}$, desenvolvida pela equipe do Centro de Inovação da Cooperativa, foi estendida para os médicos cooperados em seus consultórios, possibilitando a continuidade dos atendimentos aos seus clientes. A plataforma também foi gratuitamente cedida para a Prefeitura de Belo Horizonte, beneficiando os usuários da rede pública de saúde. Além disso, o compartilhamento regular de informações sobre o cenário epidemiológico com o poder público vem contribuindo para a tomada de decisão acerca do isolamento social, freando a disseminação de casos e preservando o sistema de saúde da capital mineira, de modo que os serviços de saúde possam atender a todos os casos suspeitos da doença.

Com o necessário isolamento social, muitos médicos cooperados que não atuam em especialidades diretamente demandadas no enfrentamento da pandemia precisaram reduzir a agenda de atendimentos e, com isso, viram sua remuneração diminuir. Para minimizar esse impacto e trazer mais tranquilidade financeira para os coopera-

15 FLAM, Samuel. Depoimento prestado por e-mail recebido em 05/01/2020.

16 Importante ressaltar que a telemedicina está regulamentada no Brasil em caráter provisório, para atender às necessidades de segurança assistencial trazidas pela pandemia. O formato oferecido pela Unimed-BH está em conformidade com os termos da autorização prevista na Lei no 13.989 de 15 de abril de 2020 e regulamentado pela Portaria $n^{\circ}$. 467, de 20 de março de 2020, do Ministério da Saúde. 
dos, a Unimed-BH ofereceu o benefício de antecipação de $70 \%$ da produção. Para aqueles que puderam continuar atendendo nos consultórios, foi pago um acréscimo no valor da consulta para a compra de equipamentos de proteção individual.

Pela abrangência da atuação da Unimed-BH com uma expressiva representatividade de clientes (1,2 milhão) entre a população de Belo Horizonte (2,5 milhões de habitantes) podemos também afirmar a contribuição indireta da cooperativa para que a capital mineira apresentasse uma das menores taxas de mortalidade entre as grandes capitais.

Além disso, as parcerias firmadas em prol da sociedade, principalmente com a Prefeitura Municipal de Belo Horizonte, ajudaram a diminuir de forma significativa o risco de contágio de grande parte da população menos favorecida. Até o dia 24 de setembro, Belo Horizonte havia registrado 1.200 mortes por Covid-19. Em São Paulo (capital), o número era 10 vezes maior na mesma data: 12.506 óbitos confirmados. E, no Rio de Janeiro, o número foi de $10.730 .{ }^{17}$

\section{Taxa de mortalidade por Covid-19 \\ Capitais com mais de 1 milhão de habitantes}

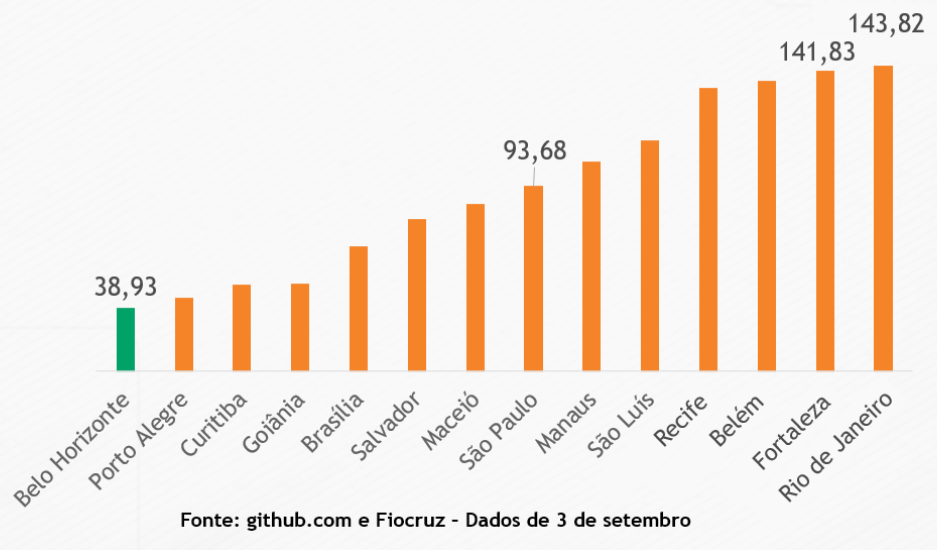

Não resta dúvida da profunda conexão das cooperativas com as comunidades nas quais atuam, além da resiliência do negócio cooperativo, sendo muitas vezes o principal ou o único meio de acesso aos serviços ofertados.

17 FLAM, Samuel. Depoimento prestado por e-mail recebido em 05/01/2020. 


\section{Conclusões}

A identidade cooperativa forjada pelos pioneiros de Rochdale, fruto dos princípios e valores que se cristalizam nas legislações mundo afora que regulam o direito cooperativo, em especial o artigo $4 .^{\circ}$ da Lei 5.764/71, determina o diferencial cooperativo.

O cooperativismo e seus valores, transformam as pessoas e as comunidades em que estão presentes, contribuindo para a transformação de toda sociedade em um sistema mais justo e equânime, com melhores oportunidades para todos.

O sistema cooperativo UNIMED forte na aplicação dos princípios e valores cooperativos, comprova o sucesso da cooperação na vida de todos que participam de forma direta ou indireta, seja prestando serviços ou recebendo a prestação dos serviços como se comprovou mais uma vez neste ano de $2020 \mathrm{com}$ a pandemia Covid-19.

A pandemia do Covid-19 comprovou a importância de termos um sistema de saúde suplementar ao sistema oficial nacional —SUS — atendendo de forma eficiente os infectados, os dois trabalhando em sintonia — público e privado- cumpriram com eficiência as diretrizes constitucionais de acesso a saúde, permitindo que o Brasil alcançasse o posto de pais que mais recuperou infectados pela Covid em todo o mundo.

Mais do que nunca os princípios e valores cooperativos oriundos dos tecelões de Rochdade a quase 200 anos estão presentes em nosso cotidiano, promovendo justiça e a paz social. Certamente será assim por todo o sempre, cada vez mais forte, mais cooperativo e colaborativo.

Por fim, citando o grande cooperativista português, Arnaldo Leite, para corroborar a importância do correto entendimento e aplicação prática dos princípios e valores cooperativos que fazem das cooperativas, sociedades únicas no ordenamento jurídico, social e econômico mundial:

Deveremos acreditar na validade das palavras de Ian MacPherson no seu trabalho designado por «Princípios cooperativos para o século XXI» onde refere que «... a eficácia das cooperativas deriva da cuidada aplicação dos valores e princípios que tornam as cooperativas únicas.

Em última análise, as cooperativas carregam consigo - nas suas estruturas e ideologia básicas- as chaves do seu próprio sucesso. A aplicação varia com o tempo e o tipo de empresa, mas a fórmula de sucesso é sempre a mesma. ${ }^{18}$

18 Leite, Arnaldo. Identidade cooperativa: Crescimento e identidade - Serão compatíveis? Revista EasyCoop, São Paulo, 2005. http://www.cooperativismo.org.br/Artigos/ View.aspx?id=507\#! 


\section{Referências bibliográficas}

Braga, Paulo Roberto Cardoso. Identidade cooperativa e o processo administrativo sancionador: princípios cooperativos e constitucionais face a aplicação da lei n. ${ }^{\circ}$ 13.506/2017. In Miranda, José Eduardo et al. Direito Cooperativo e Identidade Cooperativa - Editora Brazil Publishing, 2019.

Direito Cooperativo e Identidade Cooperativa, Editora Brazil Publishing. 1. ${ }^{\text {a }}$ edição-2019.

Carvalho Filho, José dos Santos. Manual de Direito Administrativo. 15. ${ }^{\text {a }}$. Rio de Janeiro, Lumen Juris, 2006.

Chaterina, Alejandro Martínez. Revesco: revista de estudios cooperativos, ISSN 1135-6618, n. ${ }^{\circ} 61,1995$ (Exemplar dedicado a: La identidad cooperativa), páginas 35-46.

CUNHA, José Ricardo. Sistema aberto e princípios na ordem jurídica e na metódica constitucional. 2. ${ }^{\text {a }}$ ed. Rio de Janeiro, Lúmen Juris, 2006.

FLAM, Samuel. Depoimento prestado por e-mail recebido em 05/01/2020.

García García, Francisco de Borja. The relevance of the principles of co-operatism within Co-operative Law. file:///C:/Users/Usuario/Documents/3\%20\%20PBAA/Doutrina/Cooperativismo/Francisco_de_Borja_Garc_a_Garc_a._ The_relevance_of_the_principles_of_co-operatism_Within_Co-operative_ Law.pdf

GeHRINGeR, Max. Anuário do Cooperativismo. Brasil: 2018.

LEITE, Arnaldo. Identidade cooperativa: crescimento e identidade - Serão compatíveis? - Revista EasyCoop, São Paulo, 2005.

MoRENo FontelA, Juan Luis. Revesco .(124) 2017: 114-127. Las relaciones entre los valores y principios cooperativos y los principios de la normativa cooperativa

PuLLIN, Orestes. http://www.mundocoop.com.br/artigos/o-cooperativismo-emtempos-de-pandemia-orestes-pullin-e-presidente-da-unimed-do-brasil.html

PULLIN, Orestes. http://memoria.unimed.coop.br/memoria/arquivos/detalhes/99

SCUCATO, Ronaldo Ernesto. Jornal Cooperação. Editorial. Ano XV, junho 2018. Ed. 320.

SouzA, Leonardo Rafael de. Cooperativas de crédito: regulação do CMN e os valores cooperativos. Curitiba, Juruá, 2017. https://www.unimed.coop. br/home/sistema-unimed/a-unimed / http://memoria.unimed.coop.br/ memoria/arquivos/detalhes/99

VIDIGAL, Edson. Aspectos Jurídicos das Cooperativas de Crédito. Belo Horizonte: Mandamentos, 2005, Prefácio. 


\section{Derechos de autor}

http://dec.revistas.deusto.es/

La revista Deusto Estudios Cooperativos es una revista de acceso abierto lo que significa que es de libre acceso en su integridad inmediatamente después de la publicación de cada número. Se permite su lectura, la búsqueda, descarga, distribución y reutilización legal en cualquier tipo de soporte sólo para fines no comerciales y según lo previsto por la ley; sin la previa autorización de la Editorial (Universidad de Deusto) o el autor, siempre que la obra original sea debidamente citada (número, año, páginas y DOI si procede) y cualquier cambio en el original esté claramente indicado.

\section{Copyright}

The Deusto Journal of Cooperative Studies is an Open Access journal which means that it is free for full and immediate access, reading, search, download, distribution, and lawful reuse in any medium only for non-commercial purposes, without prior permission from the Publisher or the author; provided the original work is properly cited and any changes to the original are clearly indicated. 